\title{
Synthesis of Polyaniline in the Presence of Physiological Active Compounds
}

\author{
Kuniharu Nakajima, Aohan Wang, Hirotsugu Kawashima, Hiromasa Goto* \\ Division of Materials Science, Faculty of Pure and Applied Science, \\ University of Tsukuba, Ibaraki, Japan \\ E-mail: gotoh@ims.tsukuba.ac.jp
}

Keywords: polyaniline, polysaccharide, scanning electron microscopy, fine structure

\begin{abstract}
Synthesis of polyaniline (PANI) in the presence of physiological active materials is reported. Infrared absorption, electron spin resonance, and UV-Vis optical absorption spectroscopy measurements for the resultants were carried out. Scanning electron microscopy (SEM) observations revealed the surface structures of the polymer.
\end{abstract}

\section{Introduction}

Polyaniline (PANI) has been studied for over a century [1-5]. Polyaniline has various advantages such as simple synthetic process, low cost, good stability in the air, and relatively high electrical conductivity. Polymerization mechanism [6-8], surface structure [9-18], synthesis of nano-composite [19-21], and chiroptical properties of polyaniline [22] have been studied. Polymerization of aniline under different conditions allows formation of various fine surface structures [23]. Sensor function of polyaniline for medical applications was examined [24].

Sugars and polysaccharides have been used as pharmaceutical materials, foods, molecular motors [25], and water purification [26]. Properties of polysaccharide such as oxidative reaction [27], and 3-D structure have been studied [28]. Carbon nanotubes/alginic acid [29], and PANI/polysaccharides composites have been developed [30]. Polysaccharides were employed as templates for the synthesis of polyaniline, and biocomposites was synthesized [31].

In this paper, we report synthesis of PANI in the presence of low-molecular weight physiological active compounds such as polysaccharides. Optical properties and surface structures of the PANIs thus prepared are discussed. This can be a first attempt of combination of PANI and pharmaceutical compounds in the polymerization reaction.

\section{Experimental}

\section{Materials}

Aniline (Wako Chemical, Japan) was purified by distillation. Acetic acid, adipic acid, L-ascorbic acid, cholesterol hydrogen phthalate, streptomycin, $N$-methyl pyrrolidone (NMP) (Tokyo Chemical Industry, Japan), stearic acid, retinoic acid (Wako Chemical, Japan), and ammonium persulfate (APS, $\left(\mathrm{NH}_{4}\right)_{2} \mathrm{~S}_{2} \mathrm{O}_{8}$ ) (Kanto chemical, Japan) were used as received.

\section{Instruments}

Infrared (IR) absorption spectra of the polymers were obtained by using a JASCO IR 550 Fourier transform spectrometer (Japan) with the $\mathrm{KBr}$ method. Ultraviolet-visible (UV-Vis) optical absorption spectra were recorded on a JASCO V-630 spectrophotometer. Electron spin resonance (ESR) measurements and electrical conductivity were carried out using a Bruker EMX-T ESR (USA) spectrometer and Loresta GP (measurement range: $10^{3}-10^{-7}(\mathrm{~S} / \mathrm{cm})$ ) (Japan), respectively. 
Scanning electron microscopy (SEM) observations and energy dispersive X-ray spectrometry (EDS) were performed with a JEOL JSM-521 (Japan).

\section{Pure-polyaniline}

A solution of aniline $(120 \mathrm{mM})$, sulfuric acid $(60 \mathrm{mM})$, and hydrochloric acid $(1 \mathrm{M})$ were stirred in an Erlenmeyer flask at ca. $0{ }^{\circ} \mathrm{C}$. Then, APS $(96 \mathrm{mM})$ was added to the flask, and further stirred for $24 \mathrm{~h}$ at ca. $0{ }^{\circ} \mathrm{C}$. The mixture was filtered, and washed with a large volume of water/methanol for several times. After filtration, the product was collected and dried in a vacuum for $6 \mathrm{~h}$. The resultant sample is abbreviated as pure-PANI.

\section{Polyaniline/physiological active compounds}

Aniline and the physiological active compounds (acetic acid, adipic acid, L-ascorbic acid, stearic acid, retinoic acid, cholesterol hydrogen phthalate, or streptomycin) were added to ultrapure water in an Erlenmeyer flask (aniline: $120 \mathrm{mM}$, the physiological active compound: $60 \mathrm{mM}$ ). The water solution was stirred for $3 \mathrm{~h}$ and cooled to ca. $0{ }^{\circ} \mathrm{C}$. APS was then added into the flask (96 $\mathrm{mM}$ ), and stirred for $24 \mathrm{~h}$ at $0{ }^{\circ} \mathrm{C}$. The mixture was filtered, and washed with a large volume of water/methanol for several times. After filtration, the crude product was collected and dried in a vacuum for $6 \mathrm{~h}$. Thus, seven samples with different additives were obtained. The samples are abbreviated as P1 (acetic acid), P2 (adipic acid), P3 (L-ascorbic acid), P4 (stearic acid), P5 (retinoic acid), P6 (cholesterol hydrogen phthalate), and P7 (streptomycin).

\section{Results and Discussion}

\section{IR absorption spectra}

Fig. 1 shows IR spectra of as-prepared pure-PANI, a series of PANIs (P1-P7), and PANI-base as a reference. All of the samples showed characteristic absorptions derived from structure of the PANI. The peaks in the IR are attributed to out of plane bending $\left(\gamma_{\mathrm{CH}}: 796 \mathrm{~cm}^{-1}\right)$, in plane bending $\left(\delta_{\mathrm{CH}}: 1133 \mathrm{~cm}^{-1}\right)$, stretching vibration $\left(v_{\mathrm{CN}}: 1297 \mathrm{~cm}^{-1}\right)$, and stretching vibration from quinonoid ring $\left(v_{\mathrm{Q}}: 1571 \mathrm{~cm}^{-1}\right)$ and benzenoid $\operatorname{ring}\left(v_{\mathrm{B}}: 1490 \mathrm{~cm}^{-1}\right)$ of the PANIs.
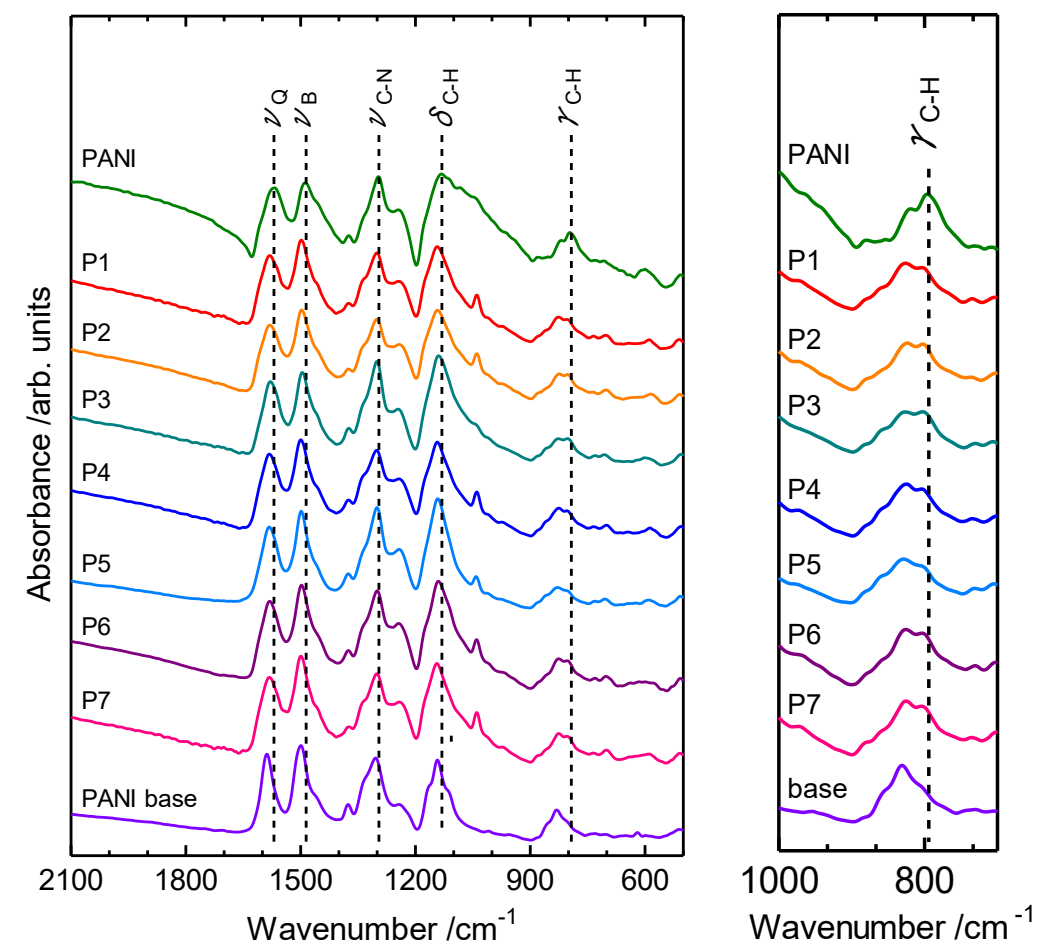

Figure 1. Infrared (IR) absorption spectra of pure-PANI, P1-P7, and PANI-base (emeraldine base). 


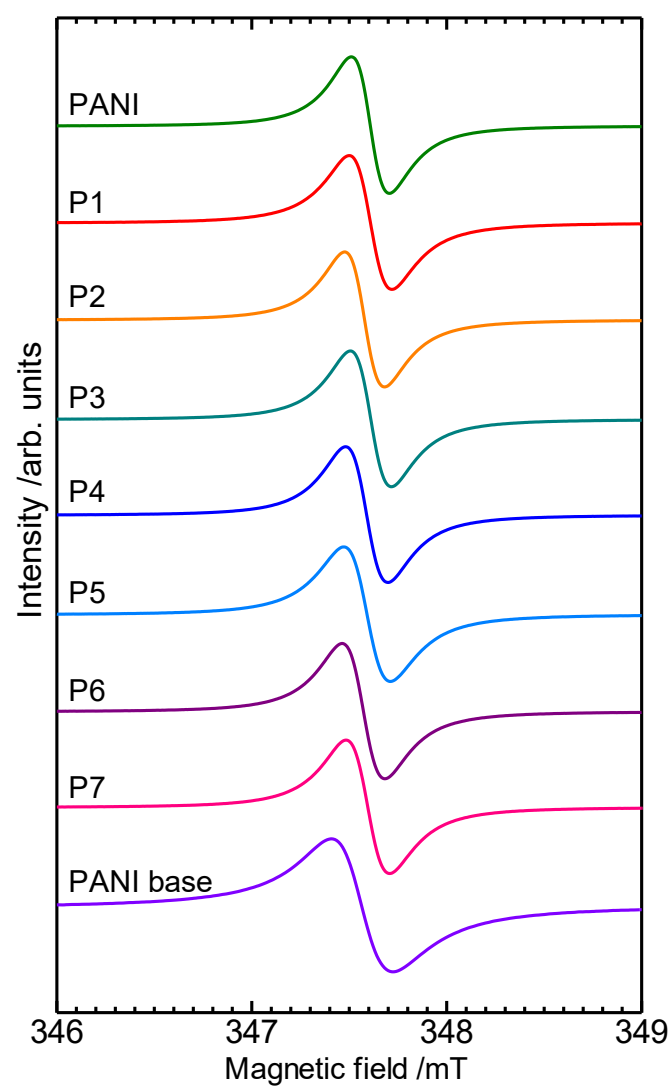

Figure 2. Electron spin resonance (ESR) spectra of pure-PANI, P1-P7, and PANI-base (emeraldine base).

\section{ESR spectra}

Polyaniline (doped form) has radical cation units along with the main-chain as polarons. Polyaniline forms several redox states. All of the samples showed ESR signal due to unpaired electrons of the radical cations in the polarons [32], Fig. 2. The $g$-values of P1-P7 are to be 2.0039 (Table 1). Line-width $\left(\Delta H_{\mathrm{pp}}\right)$ and spin concentrations are summarized in Table 1. Electrical conductivities of P1-P7 are lower than that of the pure-PANI. This may be due to the fact that spin concentrations of P1-P7 are lower than that of pure-PANI. In other words, low charge carrier density in the composite results in low conductivity (charge carrier density $\propto$ conductivity). PANI-base shows no conductivity $\left(<10^{-7} \mathrm{~S} / \mathrm{cm}\right)$.

Table 1. ESR measurement results.

\begin{tabular}{ccccc}
\hline & $g$-Value & $\Delta H_{\mathrm{pp}}(\mathrm{mT})$ & $N_{\mathrm{s}}(\mathrm{spins} / \mathrm{g})$ & Conductivity $(\mathrm{S} / \mathrm{cm})$ \\
\hline Pure-PANI & 2.00390 & 0.195 & $2.77 \times 10^{20}$ & $2.237 \times 10^{-2}$ \\
P1 & 2.00390 & 0.215 & $9.63 \times 10^{19}$ & $6.052 \times 10^{-4}$ \\
P2 & 2.00392 & 0.205 & $1.72 \times 10^{20}$ & $8.048 \times 10^{-4}$ \\
P3 & 2.00390 & 0.210 & $5.52 \times 10^{19}$ & $1.775 \times 10^{-3}$ \\
P4 & 2.00391 & 0.220 & $1.32 \times 10^{20}$ & $3.226 \times 10^{-4}$ \\
P5 & 2.00391 & 0.239 & $3.25 \times 10^{19}$ & $2.474 \times 10^{-4}$ \\
P6 & 2.00392 & 0.215 & $1.41 \times 10^{20}$ & $3.654 \times 10^{-4}$ \\
P7 & 2.00391 & 0.220 & $6.48 \times 10^{19}$ & $2.773 \times 10^{-4}$ \\
PANI-base & 2.00392 & 0.323 & $1.86 \times 10^{20}$ & - \\
\hline
\end{tabular}




\section{UV-Vis absorption spectra}

Fig. 3 displays UV-Vis optical absorption spectra of pure-PANI and P1-P7 in NMP solution. All of the samples exhibited good solubility in NMP. The absorption bands of the samples are corresponding to that of PANI-base form. The absorption band at $320-326 \mathrm{~nm}$ is ascribed to $\pi-\pi^{*}$ transition of benzene ring, and absorption band at $630-636 \mathrm{~nm}$ is due to doping band.

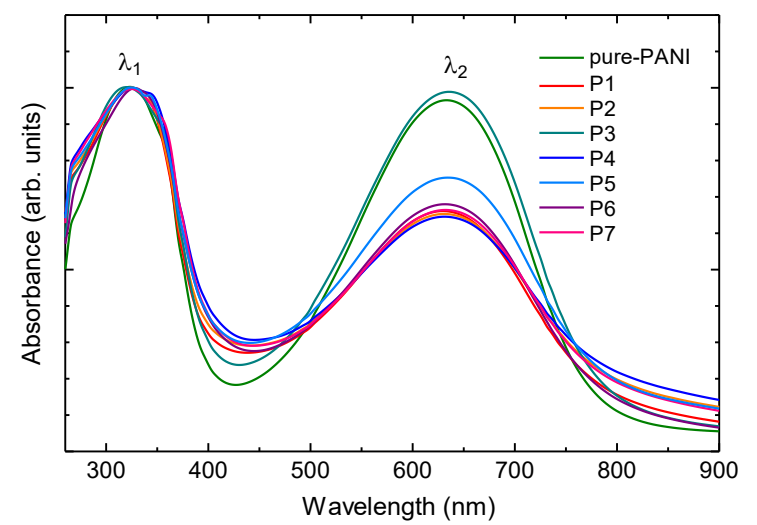

Figure 3. UV-Vis optical absorption spectra of pure-PANI and P1-P7 in $N$-methylpyrrolidone (NMP) solution $(0.05 \mathrm{~g} / \mathrm{L})$. All of the samples were pre-treated with sonification for $30 \mathrm{~min}$ and stirred for $3 \mathrm{~h}$.

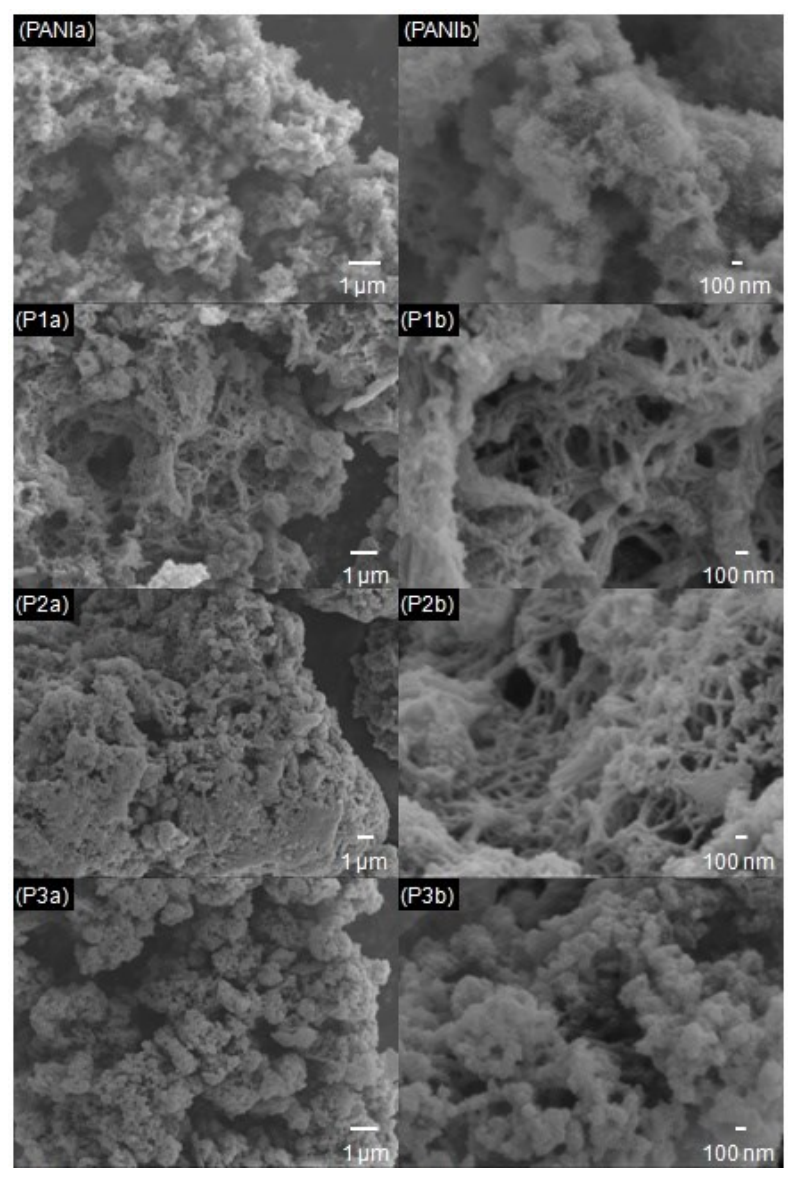




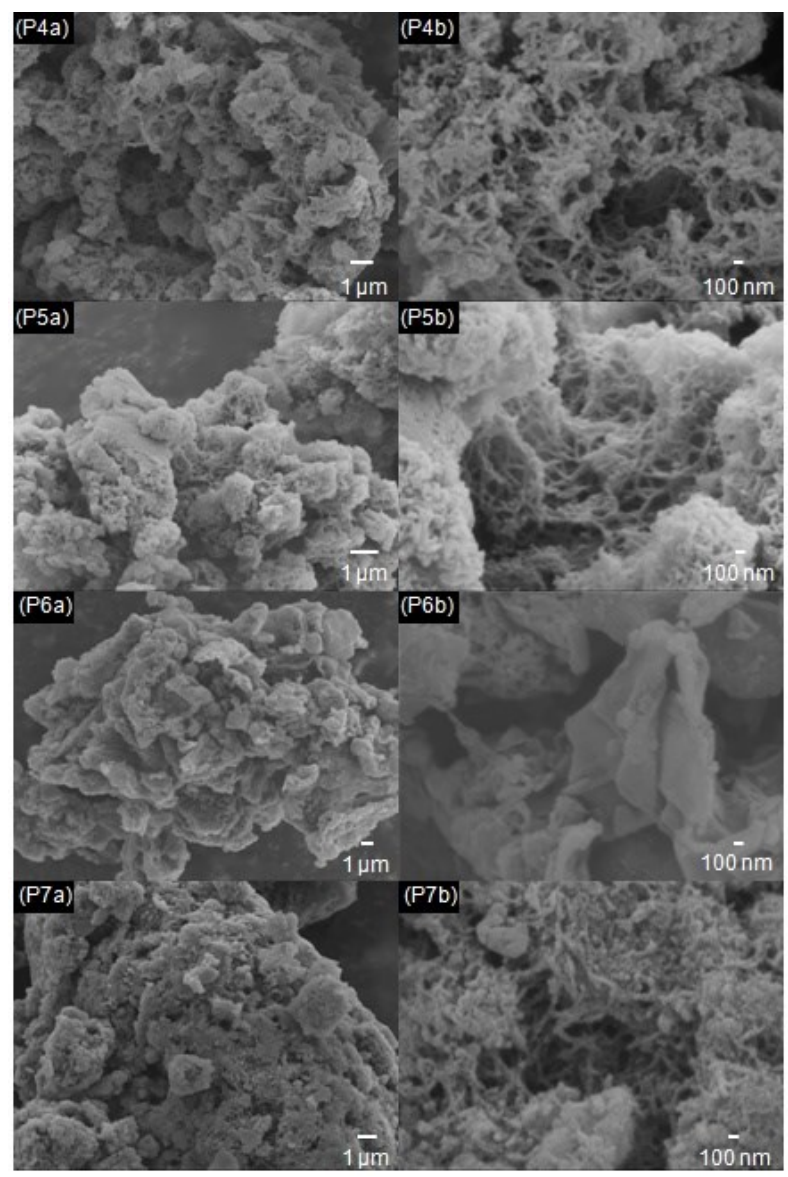

Figure 4. Scanning electron microscopy (SEM) images of pure-PANI and P1-P7.

\section{SEM observation}

Fig. 4 shows SEM images of the fine surface structure of pure-PANI and P1-P7, showing low magnification (a), high magnification (b) of the samples. The granular structure consists of tiny particles. P1, P2, P4, P5, and P7 display fiber/network structure. According to the previous research, acidity of solution of aniline in the polymerisation is the key factor to form nano-fiber/tube/rod structures of PANI. Energy Dispersive x-ray Spectroscopy (EDS) measurement evaluates that elements ratio of $\mathrm{C}, \mathrm{N}, \mathrm{O}$, and $\mathrm{S}$ (Table 3 ) for the samples are almost the same, Table 2. The fine structure may come from process of phenazine nucleus stacking. In the polymerization process, an aniline monomer becomes low molecular aniline derivative such as phenazine-type anilinium ion (Fig. 5), and the phenazines nucleus form various fine structure [33,34]. The polymerization of aniline mechanism based on the nuclei was previously studied [35-37]. In this study, the polymerization of aniline proceeds in this mechanism on the molecular substrates.<smiles>O=[N+]c1ccc(/N=c2\ccc3nc4ccccc4n(-c4ccccc4)c-3c2)cc1</smiles>

Figure 5. Phenazine-type anilinium ion structure. 
Table 2. Abundance ratio of P1-P7 obtained with EDS.

\begin{tabular}{ccccc}
\hline & \multicolumn{4}{c}{ Abundance ratio, \% } \\
\cline { 2 - 5 } & $\mathrm{C}$ & $\mathrm{N}$ & $\mathrm{O}$ & $\mathrm{S}$ \\
\hline PANI & 71.2 & 14.9 & 12.7 & 1.2 \\
P1 & 70.0 & 16.9 & 11.6 & 1.5 \\
P2 & 69.2 & 17.5 & 11.8 & 1.5 \\
P3 & 70.0 & 18.0 & 10.9 & 1.1 \\
P4 & 70.6 & 16.9 & 11.3 & 1.3 \\
P5 & 70.4 & 16.7 & 11.7 & 1.2 \\
P6 & 71.0 & 16.0 & 11.9 & 1.1 \\
P7 & 69.3 & 16.8 & 12.5 & 1.4 \\
\hline
\end{tabular}

\section{Conclusion}

Polyanilines were synthesized in the presence of low-molecular mass physiological active compounds. SEM observations revealed that the resultant PANI showed bulky fine structure or fiber/network structure. PANI/physiological active compound may function as biological active products.

\section{Acknowledgments}

We would like to thanks Research Facility Center for Science and Technology, University of Tsukuba, and Glass workshop of University of Tsukuba. This research was supported by Tsukuba Research Center for Interdisciplinary Materials Science (TIMS).

\section{References}

[1] H. Letheby, XXIX. - On the production of a blue substance by the electrolysis of sulphate of aniline, J. Chem. Soc. 15 (1862) 161-163.

[2] G. Green, E. Woodhead, CCXLIII.-Aniline-black and allied compounds. Part I, J, Chem, Soc, Trans. 97 (1910) 2388-2403.

[3] A.G. MacDiarmid, "Synthetic Metals": A novel role for organic polymers (Nobel Lecture), Angew Chem Int Ed. 40 (2001) 2581-2590.

[4] E.M. Genies, A. Boyle, M. Lapkowski, C. Tsintavis, Polyaniline: A historical survey, Synth. Met. 36 (1990) 139-182.

[5] N.V. Blinova, J. Stejskal, M. Trchova, J. Prokes, M. Omastova, Polyaniline and polypyrrole: A comparative study of the preparation, Euro. Polym. J. 43 (2007) 2331-2341.

[6] C. Laslau, Z. Zujovic, J. Travas-Stejdic, Theories of polyaniline nanostructure self-assembly: Towards an expanded, comprehensive Multi-Layer Theory (MLT), Prog. Polym. Sci. 35 (2010) 1403-1419.

[7] E.N. Konyushenko, J. Stejskal, I. Sedenkova, M. Trchova, I. Sapurina, M. Cieslar, J. Prokes, Polyaniline nanotubes: conditions of formation, Polym. Int. 55 (2006) 31-39.

[8] Z. Ding, T. Sanchez, A. Labouriau, S. Lyer, T. Larson, R. Currier, Y. Zhao, D. Yang, Characterization of reaction intermediate aggregates in aniline oxidative polymerization at low proton concentration, J. Phys. Chem. B. 114 (2010) 10337-10346.

[9] E.N. Konyushenko, M. Trchova, J. Stejskal, I. Sapurina, The role of acidity profile in the nanotubular growth of polyaniline, Chem. Pap. 64 (2010) 56-64. 
[10]N. Chiou, A. J. Epstein, A simple approach to control the growth of polyaniline nanofibers, Synth Met. 153 (2005) 69-72.

[11]G. Ciric-Marjanovic, L. Dragicevic, M. Milojevic, M. Mojovic, S. Mentus, B. Dojcinovic, B. Marjanovic, J. Stejskal, Synthesis and characterization of self-assembled polyaniline nanotubes/silica nanocomposites, J. Phys. Chem. B. 113 (2009) 7116-7127.

[12]P. Wang, E.C. Venancio, D.M. Sarno, A.G. MacDiarmid, Simplifying the reaction system for the preparation of polyaniline nanofibers: Re-examination of template-free oxidative chemical polymerization of aniline in conventional low-pH acidic aqueous media, React. Func. Polym. 69 (2009) 217-223.

[13]G. Li, Z. Wang, G. Xie, H. Peng, Z. Zhang, Synthesis of interconnected polyaniline nanofibers in catanionic micelles, J. Disp. Sci. Tech. 27 (2006) 991-995.

[14]L. Zhang, M. Wan, Chiral polyaniline nanotubes synthesized via a self-assembly process, Thin Solid Films. 477 (2005) 24-31.

[15]X. Wang, J. Liu, X. Huang, L. Men, M. Guo, D. Sun, Controlled synthesis of linear polyaniline tubes and dendritic polyaniline fibers with stearic acid, Polym. Bull. 60 (2008) 1-6.

[16]D. Chao, J. Chen, X. Lu, L. Chen, W. Zhang, Y. Wei, SEM study of the morphology of high molecular weight polyaniline, Synth Met. 150 (2005) 47-51.

[17]C. Zhou, J. Han, R. Guo, Controllable synthesis of polyaniline multidimensional architectures: from plate-like structures to flower-like superstructures, Macromolecules 41 (2008) 6473-6479.

[18]H. Goto, A. Yokoo, Polyaniline nanospheres synthesized in the presence of polyvinyl alcohol, followed by preparation of carbon nanobeads structures, J. Disp. Sci. Tech. 34 (2013) 406-410.

[19]W. Li, P.A. McCarthy, D. Liu, J. Huang, S.-C. Yang, H.-L. Wang, Toward understanding and optimizing the template-guided synthesis of chiral polyaniline nanocomposites, Macromolecules 35 (2002) 9975-9982.

[20]P.A. McCarthy, J. Huang, S.-C. Yang, H.-L. Wang, Synthesis and characterization of water-soluble chiral conducting polymer nanocomposites, Langmuir 18 (2002) 259-263.

[21]D. Müller, J.S. Mandelli, J.A. Marins, B.G. Soares, L.M. Porto, C.R. Rambo, Electrically conducting nanocomposites: preparation and properties of polyaniline (PAni)-coated bacterial cellulose nanofibers (BC), Cellulose 19 (2012) 1645-1654.

[22]G. Yuan, N. Kuramoto, Synthesis of helical polyanilines using chondroitin sulfate as a molecular template, Macromol. Chem. Phys. 205 (2004) 1744-1751.

[23]H. Goto, Synthesis of polyaniline in natural volcanic water, J. Hot Spring Sci. 60 (2010) 134-144.

[24]E.I. Gill, A. Arshak, K. Arshak, O. Korostynska, Investigation of thick-film polyaniline-based conductimetric pH sensors for medical applications, IEEE Sens. J. 9 (2009) 555-562.

[25]Y. Tsuchiya, T. Komori, M. Hirano, T. Shiraki, A. Kakugo, T. Ide, J. Gong, S. Yamada, T. Yanagida, S. Shinkai, A Polysaccharide-Based Container Transportation System Powered by Molecular Motors, Angew. Chem. 122 (2010) 736-739.

[26]C. Zhou, D. Zhang, D. Tong, L. Wu, W. Yu, S. Ismadji, Paper-like composites of cellulose acetate-organo-montmorillonite for removal of hazardous anionic dye in water, Chem. Eng. J. 209 (2012) 223-234.

[27] O. Varela, Oxidative reactions and degradations of sugars and polysaccharides, Adv. Carbohydr. Chem. Biochem. 58 (2003) 307-369.

[28]M. Nagae, Y. Yamaguchi, Three-dimensional structural aspects of protein-polysaccharide interactions, Int. J. Mol. Sci. 15 (2014) 3768-3783. 
[29]Y. Liu, C. Chipot, X. Shao, W. Cai, Solubilizing carbon nanotubes through noncovalent functionalization. Insight from the reversible wrapping of alginic acid around a single-walled carbon nanotube, J. Phys. Chem. B. 114 (2010) 5783-5789.

[30]K. Nakajima, K. Kawabata, H. Goto, Water-soluble polyaniline/polysaccharide composites: polymerization and carbonization to yield carbon micro-bubbles, Synth. Met. 194, (2014) 47-51.

[31]A.-S. Lappanen, C. Xu, J. Liu, X. Wang, M. Pesonen, S. Willfor, Anionic polysaccharides as templates for the synthesis of conducting polyaniline and as structural matrix for conducting biocomposites, Macromol. Rapid Commun. 34 (2013) 1056-1061.

[32] V.I. Krinichnyi, A.L. Konkin, A.P. Monkman, Electron paramagnetic resonance study of spin centers related to charge transport in metallic polyaniline, Synth. Met. 162 (2012) 1147-1155.

[33]J. Stejskal, I. Sapurina, M. Trchová, Polyaniline nanostructures and the role of aniline oligomers in their formation, Prog. Polym.Sci. 35 (2010) 1420-1481.

[34]A. Janošević, G. Ćirić-Marjanović, B. Marjanović, P. Holler, M. Trchová, J. Stejsk, Synthesis and characterization of conducting polyaniline 5-sulfosalicylate nanotubes, Nanotechnology 19 (2008) 135606.

[35] M. Trchova, E.N. Konyushenko, J. Stejskal, J. Kovařova, G. C'iric'-Marjanovi'c, The conversion of polyaniline nanotubes to nitrogen-containing carbon nanotubes and their comparison with multi-wall carbon nanotubes, Polym. Degrad. Stab. 94 (2009) 929-938.

[36]J.J. Langer, S. Golczak, Highly carbonized polyaniline micro- and nanotubes, Polym. Degrad. Stab. 92 (2007) 330-334.

[37]J. Stejskal, I. Sapurina, M. Trchová, E. N. Konyushenko, P. Holler, The genesis of polyaniline nanotubes, Polymer, 47 (2006) 8253-8262. 